\title{
A situação da cadeia produtiva do etanol no Brasil e em Mato Grosso do Sul a partir da crise mundial de $\mathbf{2 0 0 8}$
}

\author{
Elioterio Fachin Dias ${ }^{1}$ \\ Madalena Maria Schlindwein ${ }^{2}$ \\ Luciana Ferreira da Silva ${ }^{3}$ \\ Clandio Favarini Ruviaro ${ }^{4}$
}

\section{RESUMO}

O Brasil, considerado o maior produtor de açúcar e exportador mundial de etanol a partir da cana-deaçúcar, tem-se mostrado um laboratório mundial em larga escala de biocombustíveis. Após a crise mundial de 2008, com a descoberta do pré-sal, o setor, um dos mais prósperos da economia nacional, vem passando por uma crise econômica sem precedentes. Este artigo pretende analisar essa cadeia produtiva, à luz da Nova Economia Institucional e Economia dos Custos de Transação, das teorias da firma, governança, eficiência e competitividade, visando identificar possíveis políticas públicas orientadas para a recuperação do setor. Analisando, metodologicamente, à luz das teorias aplicadas sobre a cadeia produtiva da cana e as agroindústrias do setor, na área de abrangência do estado de Mato Grosso do Sul, à Região Centro-Sul, no território brasileiro; e das políticas adotadas pelas organizações e instituições e demais agentes envolvidos, com levantamentos de dados documentais e estatísticos (BIOSUL, CANASAT, IBGE, UDOP e UNICA), a partir da safra 2001/02 até a safra 2013/14.

Palavras-chaves: Nova Economia Institucional; Economia dos Custos de Transação; Competitividade e Eficiência.

\begin{abstract}
Brazil is the largest sugar producer and exporter of ethanol from sugar cane. The country has proved a global laboratory-scale biofuel. After the global crisis of 2008, with the discovery of pre-salt, the sector, one of the most prosperous of the national economy, is going through an unprecedented economic crisis. This article aims at analyzing this chain, the light of the New Institutional Economics and Transaction Cost Economics, theories of the firm and stakeholders, governance, efficiency and competitiveness in order to identify possible public policies for the recovery of the sector. Analyzing, methodologically, to the theories applied to the supply chain and the cane agribusiness sector, the coverage area of the state of Mato Grosso do Sul, the South Central Region, in Brazilian territory; and policies adopted by organizations and institutions and other stakeholders, with surveys documentary and statistical data (BIOSUL, CANASAT, IBGE, UDOP e UNICA) in the period 2001-2013.
\end{abstract}

Keywords: New Institutional Economics; Transaction Cost Economics; Competitiveness and Efficiency.

\footnotetext{
${ }^{1}$ Mestre, Professor dos Cursos de Direito, Ciências Contábeis e Engenharia Ambiental da Universidade Estadual de Mato Grosso do Sul (UEMS); Mestrando em Agronegócios pela Universidade Federal da Grande Dourados (UFGD); Bolsista da FUNDECT/CAPES.

${ }^{2}$ Doutora, Professora do Programa de Pós-Graduação em Agronegócios da UFGD.

${ }^{3}$ Doutora, Professora do Curso de Engenharia Ambiental da Universidade Estadual de Mato Grosso do Sul (UEMS) e do Programa de Pós-Graduação em Agronegócios da UFGD.

${ }^{4}$ Doutor, Professor do Programa de Pós-Graduação em Agronegócios da UFGD.
} 


\section{INTRODUÇÃO}

O crescimento da conscientização ambiental, as preocupações com o aquecimento global, o alto preço do petróleo e o desenvolvimento dos veículos bicombustíveis (flex fuel), em 2003, fizeram com que o mundo se voltasse para a busca de fontes alternativas de combustível e energia. Com o ressurgimento do álcool como combustível, rebatizado de etanol, o transformaram no principal biocombustível produzido no mundo, fazendo com que sua demanda e produção atingissem níveis historicamente elevados, abrindo novas perspectivas para o setor (FAGUNDES, 2013; MSANGI, et. al., 2007).

O Brasil, como detentor do domínio pleno da tecnologia de produção de biocombustíveis e com grande potencial de produtividade, é considerado o maior produtor e exportador mundial de etanol e açúcar, produzido a partir da cana-de açúcar (CNI, 2012; CENTENARO, 2011); e, "tem se mostrado um laboratório mundial para as experiências em larga escala de biocombustíveis", com produção de bioetanol por mais de 420 unidades processadores, na safra 2009-2010, mobilizando 4,5 milhões de trabalhadores no país (ROSÁRIO, et. al., 2012, p. 120). Entretanto, após a crise financeira mundial de 2008/2009, com a descoberta do petróleo do pré-sal no litoral brasileiro, o setor sucroenergético, um dos mais prósperos da economia nacional, vem passando por uma crise econômica sem precedentes (NEVES; TROMBIN, 2014).

O governo brasileiro, no intuito de conter os impactos da crise no Brasil, passou a controlar artificialmente o preço da gasolina, mantendo-o sem reajustes, obrigando a Petrobrás a praticar preços abaixo do mercado internacional. Além disso, em 2012, a União desonerou a gasolina do pagamento da Contribuição de Intervenção no Domínio Econômico CIDE, diminuindo a diferenciação tributária da gasolina em relação ao etanol (MILANEZ, 2013).

Para Nastari (2013, p. 3), ao privilegiar o controle de preço, além de reduzir a tributação da CIDE sobre a gasolina, a política nacional "tem induzido os agentes econômicos na direção contrária às metas de avanço no uso de biocombustíveis".

Ao discorrer sobre a competitividade e a coordenação de sistemas agroindustriais, Farina questiona: “Qual o papel da política pública nesse contexto?”. No mesmo sentido, Shirley (1997, apud FARINA, 1999, p. 148) levanta as seguintes questões: "Quais são as causas da mudança institucional? Como se podem substituir instituições fracas (...)? O que pode ser feito para melhorar o desempenho dos governos?" 
Com base nas questões levantadas, pretende-se analisar a cadeia produtiva da cana-deaçúcar, à luz da Nova Economia Institucional (NEI) e da Economia dos Custos de Transação (ECT), visando identificar possíveis políticas públicas orientadas para a restauração, a manutenção e a competitividade do setor.

\section{FUNDAMENTAÇÃO TEÓRICA}

\subsection{Teorias da Nova Economia Institucional e da Economia dos Custos de Transação}

A Nova Economia Institucional desenvolvida por Coase, em 1937, com a publicação de seu trabalho "A natureza da firma", tornou-se um marco, ao analisar as formas de coordenação, o mercado e a firma; além de investigar os motivos que levam à sua existência, procurando entender seus limites (MARQUES; PAULILLO, 2009; FARINA, et. al., 1997).

Para Marques e Paulillo (2009, p. 26), a Nova Economia Institucional "preocupa-se com as regras e os sistemas de governança desenvolvidos para regular ou gerenciar trocas econômicas".

No mesmo sentido, Farina (1999, p. 148) esclarece que a Nova Economia Institucional procura "identificar qual a melhor forma de organização das transações econômicas", e, que "é crescente o reconhecimento de que diferentes formas de organizar a produção têm impactos significativos sobre a capacidade de reação a mudanças no ambiente competitivo”.

Por ambiente institucional, "entende-se o conjunto de regras políticas, sociais e legais, que estabelecem as bases para produção e distribuição" (WILLIAMSON, 1994, Apud MARQUES; PAULILLO, 2009, p. 26). As instituições consistem em normas formais e informais. Formais, as constituições, leis e direitos de propriedade; informais, as tradições, costumes, etc.

Em seus estudos, Coase (1937), buscava compreender os custos sociais nas transações econômicas das organizações (firmas), não as considerando como "mera" função de produção, mas como espaços de relações orgânicas entre agentes que se relacionam através de contratos explícitos (formais) ou implícitos (informais). Sustentava que às organizações econômicas competiria ser o foro natural para coordenar as transações, uma vez que existiriam custos associados ao seu funcionamento. (MARQUES; PAULILLO, 2009).

Segundo North (1992), pode-se pensar como custos de transação, todos aqueles custos incorridos na operação de um sistema econômico. Advogados, banqueiros, contadores, 
funcionários, encarregados, gerentes e politicos, são algumas das profissões, em grande parte ou totalmente envolvidos em transações; isto é, são partes essenciais de um sistema econômico.

O ressurgimento da Nova Economia Institucional de Coase se deve a Williamson, com a publicação de seu trabalho "Mercados e hierarquias" (1975), que construiu a teoria da Economia dos Custos de Transação (ECT), a partir de abordagens do direito, da economia e dos estudos organizacionais, sustentando-a em dois pressupostos: no ambiente institucional e os mecanismos de governança. É fundamental, para o estudo das organizações, a análise de custos de transação, devendo-se ter como foco a sua eficiência (VILPOUX, 2014; MARQUES; PAULILLO, 2009).

Para Wilkinson (1999), segundo a teoria das convenções, as regras não são anteriores à ação, representam uma resposta a problemas que surgem no interior de uma coordenação de atores. São representações dinâmicas de negociação e dependem da existência de pontos em comum entre os envolvidos. Para Boaventura et al. (2009, p. 293), a teoria da firma, é abordada na área de finanças, cujo objetivo da empresa é a maximização dos lucros, baseada na teoria da maximização da riqueza dos acionistas.

\subsection{Teorias da governança e da competitividade}

O termo 'governança' provém das teorias da firma e da 'governança corporativa'. Primeiramente, o termo foi utilizado para descrever mecanismos de coordenação e controle de redes internas e externas às empresas, sendo amplamente usada para designar os processos e os complexos de tomada de decisão, a descentralização da autoridade e das funções ligadas ao ato de governar, assim como a parceria entre o público e o privado. O conceito se refere às diversas formas pelas quais os indivíduos e as organizações públicas e privadas gerenciam seus problemas comuns, acomodando os interesses conflitantes ou diferenciados (CASSIOLATO; SPAZIRO, 2003; MILANI; SOLINIS, 2002).

Por mecanismo de governança, entende-se o arranjo entre unidades econômicas que determinam o modo como essas unidades podem cooperar ou competir (NORTH; 1994). A incerteza corresponde ao desconhecimento dos possíveis eventos futuros. Quanto maior a incerteza, maiores os custos de transação (NORTH, 1994).

Alguns mercados convencionais estão, geralmente, associados a cadeias globais de commodities, controladas por empresas transnacionais livres de qualquer vínculo com as 
localidades ou Estados-nacionais, cujas estratégias são continuamente apropriadas pelos atores que dominam esses mercados, pautando cada vez mais a diferenciação dos produtos. "Estamos diante de um movimento dinâmico que tem resultado na crescente hibridização dos mercados e atores econômicos, o que impede a delimitação de fronteiras rígidas e estanques" (NIEDERLE, 2009, p. 31). Por competitividade entende-se "a capacidade da firma em implementar estratégias concorrenciais, que lhe permitam ampliar ou conservar sua posição no mercado" (GIANEZINI, M., et. al, 2013, p. 16). Segundo Farina (1999, p. 149), a competitividade pode ser definida "como a capacidade sustentável de sobreviver e, de preferência, crescer em mercados correntes ou em novos mercados".

Para Harrison et. al. (1998), a escola de gestão estratégica define a competitividade como a capacidade de criar de forma rentável e gerar valor através de liderança de custo ou diferenciação do produto. Esta abordagem implica dizer que a competitividade está diretamente relacionada com os fatores que influenciam a estrutura de custos e a demanda de uma empresa.

Segundo North (1992), para a eficiência ao longo prazo, é essencial que as instituições tenham flexibilidade política e econômica e se adaptem às novas oportunidades. A tomada de decisão descentralizada permitirá à sociedade explorar as muitas alternativas para solução dos problemas. Para se atingir mercados eficazes competitivos, as instituições não devem apenas fornecer medições de baixo custo dos direitos de propriedade e das leis de falência, mas devem incentivar a tomada de decisão descentralizada.

\section{PROCEDIMENTOS METODOLÓGICOS}

Para a realização do presente artigo, quanto aos métodos, optou-se, pelo estudo exploratório. Quanto aos procedimentos, pela realização de estudos sobre a revisão dos conceitos da teoria da Nova Economia Institucional (NEI) e da Economia dos Custos de Transação (ECT), aplicados sobre a cadeia produtiva da cana-de-açúcar e as agroindústrias do setor, na área de abrangência do estado de Mato Grosso do Sul, com a respectiva caracterização da área e levantamento de dados documentais e estatísticos, a partir da safra 2001/02 até a safra 2013/14.

As leituras foram realizadas com auxílio de ferramentas de pesquisa on line, aliadas aos dados (BIOSUL, CANASAT, IBGE, UDOP e UNICA), analisando a luz das teorias e das políticas adotadas pelas organizações e instituições e demais agentes envolvidos. 
A área objeto do estudo centra-se no Estado de Mato Grosso do Sul, o $6^{\circ}$ estado do país em extensão territorial, com uma área de $35.145,532 \mathrm{~km}^{2}$, localizado ao sul da Região Centro-Oeste, com uma população estimada de 2.597.267 habitantes, em 2013 (IBGE, 2013; CASTILHO, 2013, p. 43; SEMAC/SUPLAN, 2014, p. 4), conforme Figura 1.

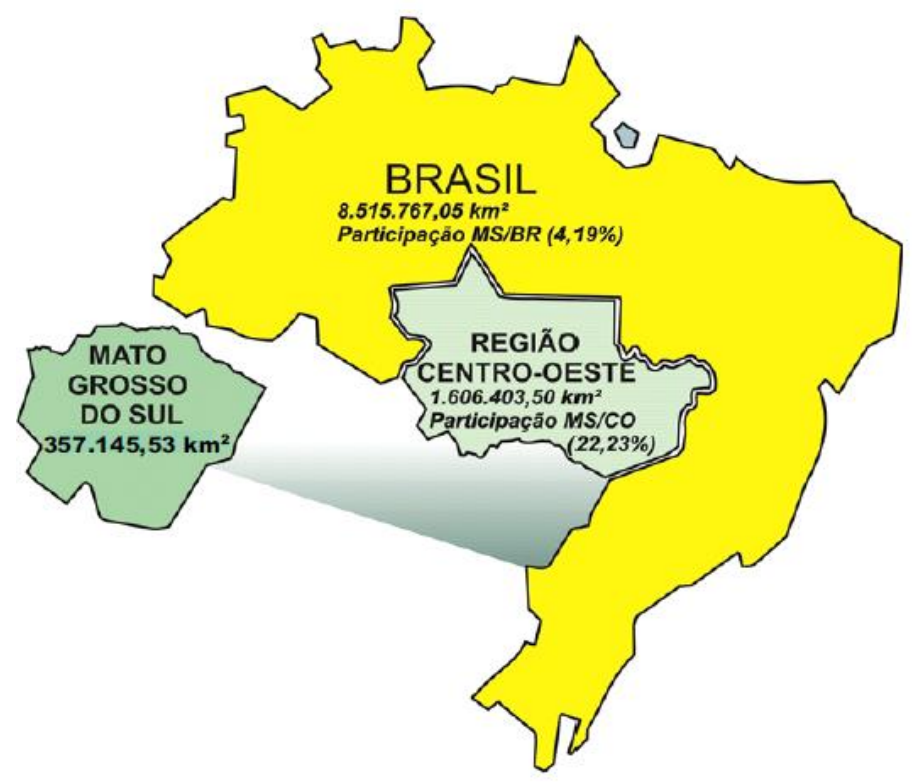

Figura 1. Estado de Mato Grosso do Sul - Brasil. Fonte: SEMAC/SUPLAN (2014, p. 4).

O Mato Grosso do Sul tem atraído investidores do setor sucroenergético, devido às suas terras férteis, ao seu clima e sua posição geográfica, destacando-se nacional e internacionalmente, com crescimentos significativos, principalmente, pela substituição das áreas degradadas antes destinadas à pecuária (CENTENARO, 2012).

\section{RESULTADOS E DISCUSSÃO}

\subsection{Situação atual do setor sucroenergético no Brasil}

Segundo dados da Análise de Conjuntura dos Biocombustíveis (EPEA, 2014), a fabricação de etanol no Brasil atingiu, em 2013, o patamar de 27,7 bilhões de litros de etanol, com uma variação positiva de $18 \%$ a mais que o produzido em 2012, e próximo da produção de 27,9 bilhões (2010).

A cadeia produtiva da cana-de-açúcar movimentou, na safra 2013/2014, em torno de US\$ 107 bilhões, contribuindo com cerca de US\$ 8,5 bilhões de impostos. Além da 
comercialização de 14,54 bilhões de litros de etanol, e 11,13 milhões de toneladas de açúcar para o mercado interno, as exportações de etanol somaram US\$ 1,67 bilhão, e 26,63 milhões de toneladas de açúcar (NEVES; TROMBIM, 2014).

O Brasil produziu, na safra 2000/01, 16,02 milhões de toneladas de açúcar, e 10,52 milhões de metros cúbicos de etanol, sendo 5,58 milhões de metros cúbicos de etanol anidro e 4,93 milhões de metros cúbicos de etanol hidratado. Atingindo, na safra 2013/2014, 37,85 milhões de toneladas de açúcar, e 28,03 milhões de metros cúbicos de etanol total, sendo 16,19 milhões de metros cúbicos de etanol anidro e 11,83 milhões de metros cúbicos de etanol hidratado (Gráfico 1).

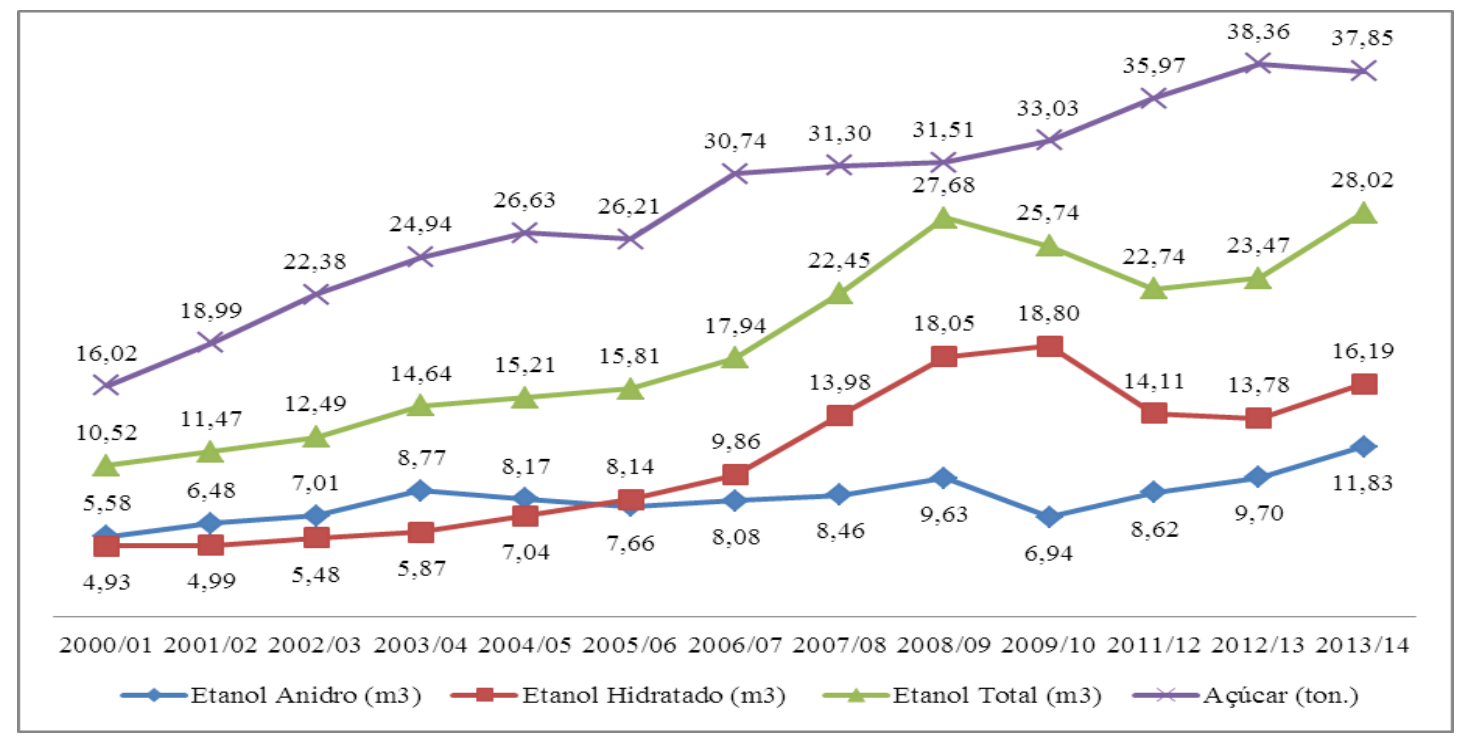

Gráfico 1. Produção brasileira de açúcar e etanol (em milhões)

Fonte: Elaboração do autor a partir: UDOP; DCCA/SPAE/MAPA (2014)

Segundo dados do Ministério do Desenvolvimento, Indústria e Comércio Exterior - MDIC, no mês de julho/2014, o Brasil exportou 90,7 milhões de litros de etanol com uma queda de 74,1\%, comparando-se com a exportação de julho/2013, ou seja, 350,5 milhões de litros. A receita cambial resultante da venda do biocombustível alcançou US\$ 57,3 milhões, no mês de julho/2014, um recuo de 74,4\% ante os US\$223,5 milhões registrados em julho/2013 (BIOSUL, 2014).

Em julho/2014, o Brasil exportou 2,488 milhões de toneladas de açúcar, volume 34,1\% maior que as 1,855 milhão de toneladas embarcadas em junho do mesmo ano; e, 8,3\% superior ante as 2,297 milhões de toneladas registradas em julho/2013. A receita obtida com a exportação total de açúcar em julho/2014 foi de US\$ 995,8 milhões, 31,9\% maior que a registrada em junho/2014 (US\$ 754,8 milhões) e 3,3\% acima dos US\$ 964,3 milhões apresentados em julho do ano anterior (BIOSUL, 2014a). A Companhia Nacional de Abastecimento (CONAB, 2014) apurou que a área cultivada com 
cana-de-açúcar na safra 2014/2015 será de 9,13 milhões de hectares no país, ou seja, um crescimento de $3,6 \%$ ou 318,67 mil hectares, em relação à safra anterior.

O Estado de São Paulo permanece como o maior produtor com 51,31\% (4.515.360 hectares) da área plantada, seguido por Goiás com 9,30\% (818.390 hectares), Minas Gerais com 8,88\% (781,920 hectares), Mato Grosso do Sul com 7,09\% (624.110 hectares), Paraná com 7,05\% (620.330), Alagoas com 5,03\% (442.590 hectares) e Pernambuco com 3,25\% (286.030 hectares), de acordo com o Gráfico 3. Nos demais estados produtores, as áreas são menores, com representações abaixo de $3 \%$ (CONAB, 2014).

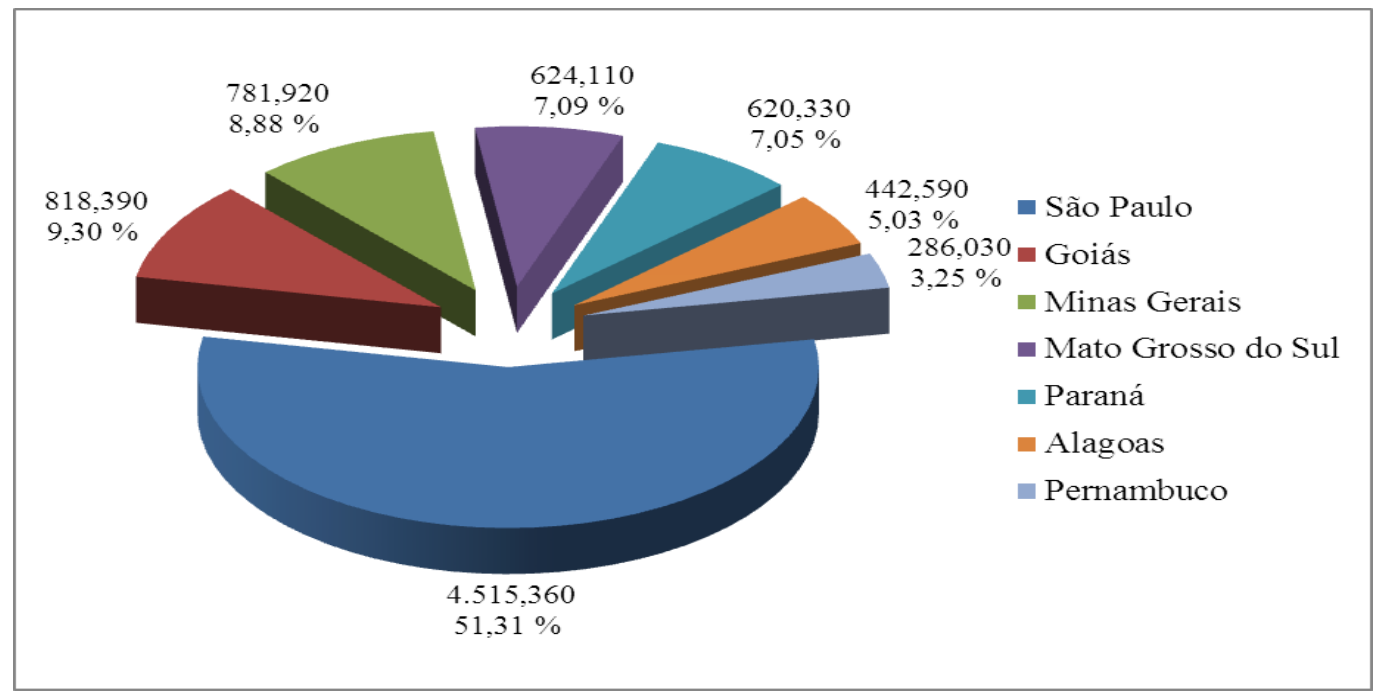

Gráfico 2. Área plantada de cana-de-açúcar, por estados, em mil hectares Fonte: Elaboração própria a partir da Conab (2014)

Apesar disso, a União da Indústria da Cana-de-Açúcar (UNICA, 2014) aponta que o faturamento global por tonelada processada sofreu queda nos últimos anos. O faturamento por tonelada foi de $\mathrm{R} \$ 116,01$, na safra $2011 / 2012$, para 106,08 na safra 2012/2013, e $\mathrm{R} \$ 100,07$ na safra 2013/2014 (Figura 2).

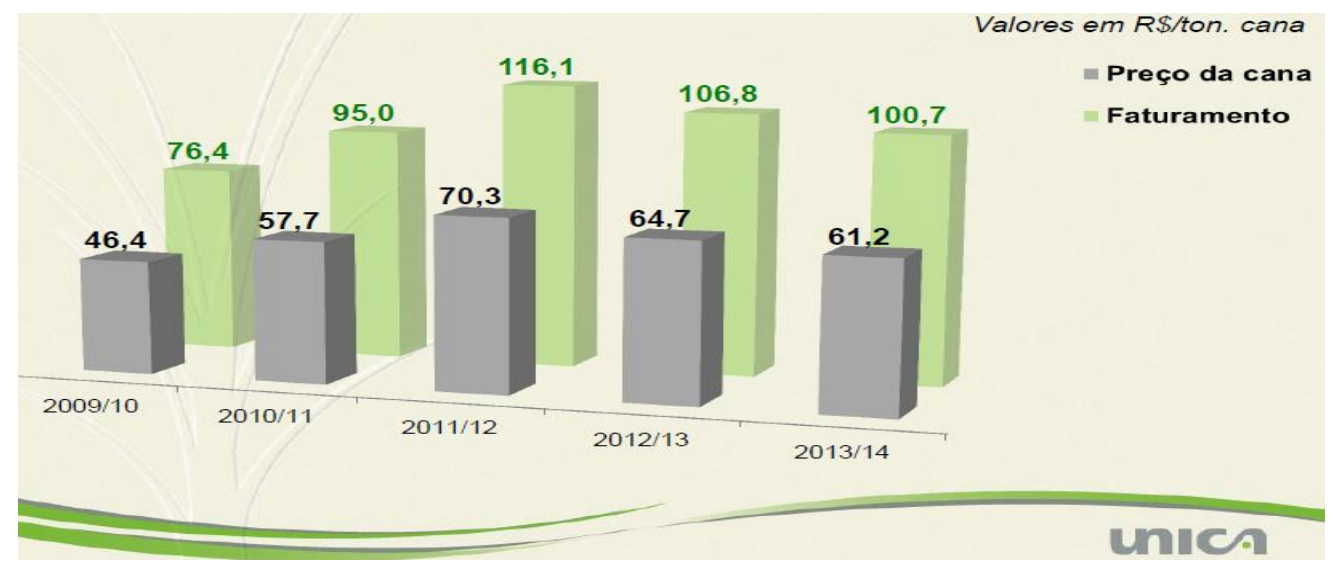

Figura 2. Preço médio da cana-de-açúcar e faturamento Fonte: Consecana; Unica (2014) 
O efeito correlato são os prejuízos e o desestímulo do setor, que tem como principal produto, o etanol, que compete com a gasolina subsidiada pelo governo federal. Para a União dos Produtores de Bioenergia (UDOP), o descompasso financeiro nas usinas brasileiras é fruto de uma soma de fatores, resultado de apostas equivocadas do governo federal, a partir da descoberta de petróleo do pré-sal (AGUIAR, 2014).

De acordo com a SCA Etanol do Brasil, uma das maiores tradings do país, na atual temporada, a exportação de etanol do Brasil deve atingir 1,7 bilhão de litros, apresentando uma queda de $35 \%$ ante a safra anterior, principalmente em função de menores embarques para os Estados Unidos (AGUIAR, 2014).

Segundo dados do Fórum Nacional Sucroenergético ${ }^{5}$, que representa importantes entidades de 15 estados produtores de açúcar, etanol e bioenergia, o setor fechou, desde a crise mundial, na região Centro Sul do país, mais de 80 mil postos de trabalho; acumulando R\$ 60 milhões de dívidas, faturando somente R \$ 65 bilhões (BIOSUL, 2014).

Segundo dados da União da Indústria da Cana-de-Açúcar (UNICA, 2014), o setor sucroalcooleiro do Centro-Sul poderá atingir o número de 58 unidades produtoras fechadas, até o final de 2014 (Gráfico 3).

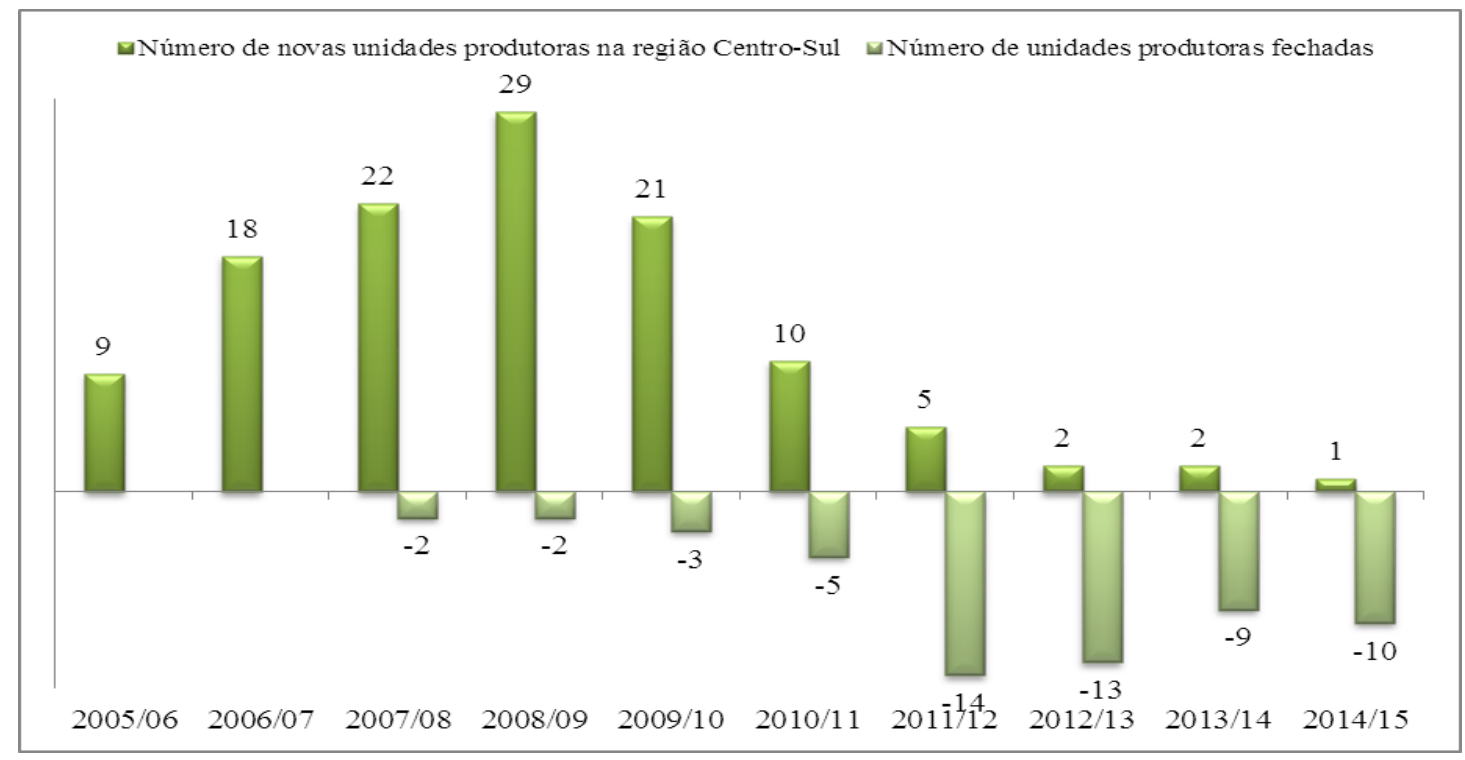

Gráfico 3. Unidades produtoras da região-Sul novas e fechadas Fonte: Elaboração a partir de Unica (2014)

\footnotetext{
${ }^{5}$ Entidades que integram o Fórum Nacional Sucroenergético: Associações de Produtores de Bioenergia do Estado do Paraná (Alcopar) e de Bionergia de Mato Grosso do Sul (Biosul), os Sindicatos das Indústrias do Açúcar e do Álcool no Estado de Alagoas (Sindaçúcar/AL), das Sucroalcooleiras de Mato Grosso (Sindálcool), das Sucroenergéticas de Minas Gerais (Siamig) e de Fabricação de Etanol do Estado de Pernambuco (Sindaçúcar/PE), o Sindicato da Indústria de Fabricação de Etanol do Estado de Goiás (Sifaeg), as Uniões dos Produtores de Bioenergia (Udop) e da Indústria de Cana-de-açúcar (Unica) e os sindicatos do Maranhão, Piauí, Rio Grande do Norte, Bahia e Paraíba.
} 
Segundo Valente et al. (2012), as estimativas de investimentos em equipamentos agrícolas e industriais em greenfield (somente produção de etanol) de quatro milhões de toneladas de cana-de-açúcar, era de R $\$ 739$ milhões, referentes aos gastos com aquisição de equipamentos agrícolas e industriais. As usinas para produção de etanol (mix de $60 \%$ do caldo) e açúcar (mix de 40\%), implantada no Centro-Oeste, com capacidade de processamento anual de quatro milhões de toneladas de cana-de-açúcar, a estimativa de custo total dessa usina greenfield era de R $\$ 817$ milhões.

Para Valente et. al. (2012, p. 136), “os investidores formaram expectativas positivas para o futuro do mercado, desencadeando uma série de decisões de investimento entre 2003 e 2008". Todavia, o cenário atual é desanimador, pois os investimentos encerraram-se com a crise mundial de 2008/09, os custos de produção aumentaram e a rentabilidade diminuiu, gerando a insegurança dos empresários e um alto e crescente endividamento do setor, provocando a paralisação das atividades e a decretação de falência ou recuperação judicial de dezenas de usinas; e, consequentemente, a redução de trabalhadores formais. Segundo Neves (2014, p. 204), "mais de 64 mil postos de trabalho perdidos, nas usinas de açúcar"; e, "mais de 20 mil, nas destilarias de etanol”.

\subsection{O setor sucroenergético no estado de Mato Grosso do Sul}

O clima e a posição geográfica adequada fazem do MS uma região atrativa para as indústrias de cana-de-açúcar, sendo notável o aumento dos canaviais e a implantação de novas usinas, o que mostra o grande potencial de expansão do estado. Em 1979, existiam apenas duas usinas de açúcar e álcool; em 1983, aumentaram para oito. No período de 1983 a 2006, foram instaladas apenas duas unidades de produção no estado, ampliando, de 2007 a 2013, para vinte e quatro (CENTENARO, 2012; UDOP, 2014).

Tabela 1. Usinas de Áçucar, Etanol e Bioeletricidade de Mato Grosso do Sul

\begin{tabular}{|l|l|l|l|}
\hline \multicolumn{1}{|c|}{ Usina } & \multicolumn{1}{c|}{ Razão Social } & \multicolumn{1}{c|}{ Municipio } \\
\hline & Aurora & Usina Aurora Alúcar e Álcool Ltda & Anaurilandia \\
\hline & Adecoagro - Unidade Angélica & Angélica Agroenergia Ltda & Angélica \\
\hline Alcoovale & Alcoolvale S/A - Álcool e Açúcar & Aparecida do Taboado \\
\hline & Usina Laguna & Usina Laguna Alcool e Açucar Ltda & Batayporã \\
\hline & Raízen - Caarapó & Raizen Caarapó S.A - Açucar e Alcool & Caarapó \\
\hline & Iaco Agrícola & Iaco Agricola S/A & Chapadão do Sul \\
\hline & Odebrecht Agroind. - Costa Rica & Brenco Cia. Bras. Energia Renovavel & Costa Rica \\
\hline Odebrecht Agroind. - Eldorado & Usina Eldorado S/A & Deodápolis \\
\hline & São Fernando & São Fernando Áçúcar e Alcool Ltda & Dourados \\
\hline & Rio Paraná & Usina Rio Paraná S/A & Eldorado \\
\hline & Fátima do Sul Agro-Energ. S/A & Fátima do Sul Agro-Energetica S/A & Fátima do Sul \\
\hline
\end{tabular}




\begin{tabular}{|l|l|l|}
\hline Dcoil & Destilaria Centro Oeste Iguatemi Ltda & Iguatemi \\
\hline Adecoagro - Ivinhema & Adecoagro Vale do Ivinhema S/A & Ivinhema \\
\hline Biosev - Maracaju & Biosev S/A & Maracaju \\
\hline Tonon - Vista Alegre & Tonon Bioenergia S/A & Maracaju \\
\hline Usinavi & Usina Navirai S/A - Açucar e Alcool & Navirai \\
\hline Odebrecht Agroind. - Santa Luzia 1 & Agroenergia Santa Luzia S/A - Matriz & Nova Alvorada do Sul \\
\hline Santa Helena & Energética Santa Helena S/A & Nova Andradina \\
\hline Terra Verde & Terra Verde Bioenergia Partic.S/A & Nova Andradina \\
\hline Bunge Brasil - Monteverde & Monteverde Agro-Energética S/A & Ponta Porã \\
\hline Biosev - Rio Brilhante & Biosev S/A - Faz. Sta Maria & Rio Brilhante \\
\hline Biosev - Passa Tempo & Biosev S/A & Rio Brilhante \\
\hline Sonora & Sonora Estancia S/A & Sonora \\
\hline Vicentina & Central Energética Vicentina Ltda & Vicentina \\
\hline
\end{tabular}

Fonte: Elaboração própria a partir de UDOP (2014)

O Mato Grosso do Sul produzia, na safra 2001/02, 255,5 $\mathrm{mil} \mathrm{m}^{3}$ de etanol; e, 254,8 mil toneladas de açúcar, atingindo na safra 2013/14, os totais de 2,230 mil m³ de etanol; e, 1.368 mil toneladas de açúcar (Gráfico 4).

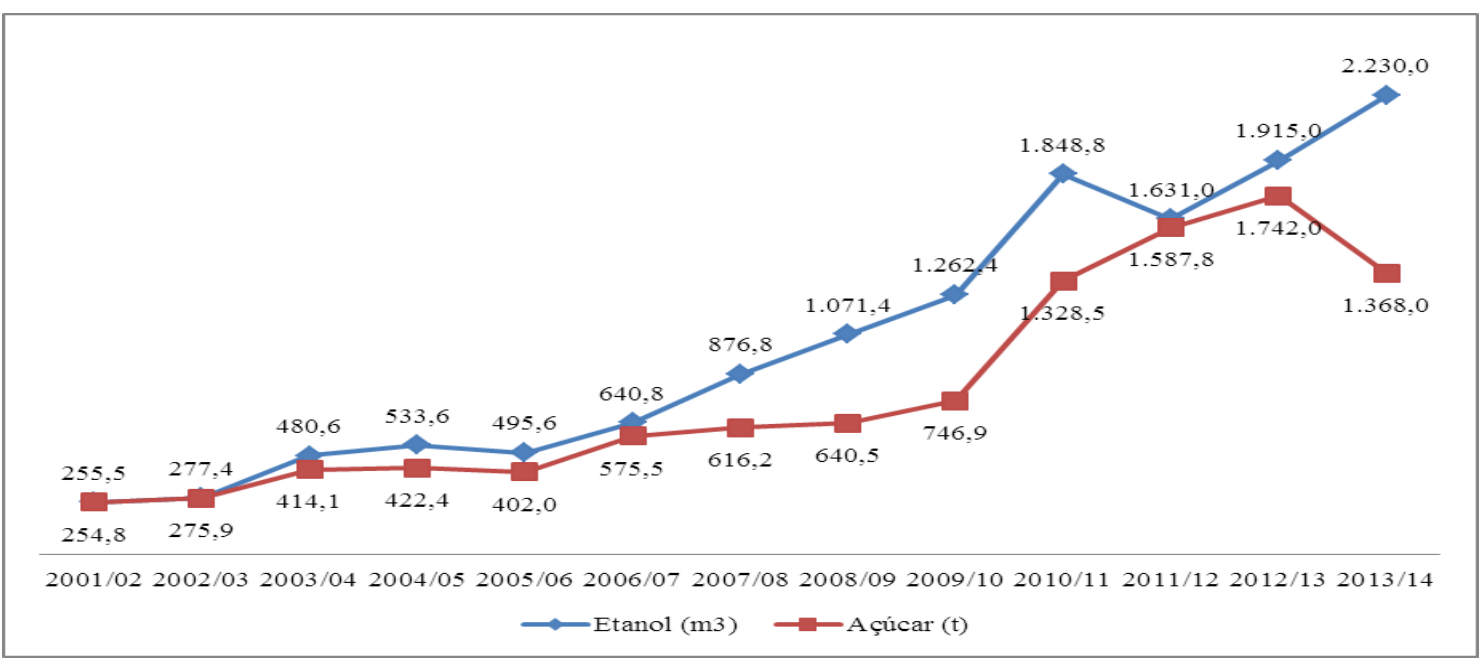

Gráfico 4. Produção de etanol e açúcar no MS

Fonte: Elaboração própria a partir da BIOSUL (2014)

O setor sucroenergético é considerado um dos mais importantes da economia sulmato-grossense, todavia, sofre os mesmos efeitos da crise nacional que paira sobre as usinas de cana-de-açúcar do país.

A Biosev Bioenergia, uma das líderes mundiais no setor sucroalcooleiro e segunda maior no Brasil, fruto da associação, em outubro de 2009, entre duas importantes empresas, LDC Bioenergia, pertencente ao grupo Louis Dreyfus Commodities, com a Santelisa Vale, uma das maiores companhias nacionais na produção e processamento de cana-de-açúcar, com onze unidades industriais, informou à Comissão de Valores Mobiliários - CVM, um prejuízo 
líquido de $\mathrm{R} \$ 1,017$ bilhão, no $4^{\circ}$ trimestre da safra 2013/14, e no acumulado do exercício, uma perda liquida de $\mathrm{R} \$ 1,466$ bilhão (BATISTA, 2014).

A Bunge, outra relevante empresa no setor sucroenergético brasileiro desde 2007, está se retirando do segmento de produção de açúcar no Brasil. "Os planos não saíram como o previsto por causa da queda dos preços internacionais do açúcar e dos subsídios dados à gasolina pelo governo, que reduzem a competitividade do etanol", afirmou (AGENCIA ESTADO, 25/4/2014).

Nos últimos meses, encerraram-se em torno de mil postos de trabalho na Odebrecht Agroindustrial, braço sucroalcooleiro do Grupo Odebrecht. O grupo pretende ainda, desativar algumas usinas, a partir da safra 2015/2016, se a situação não se normalizar. Ainda não se sabe quais usinas deixarão de operar - de São Paulo, Goiás ou Mato Grosso do Sul (BATISTA, 2014).

A Usina São Fernando, de Dourados/MS, é a primeira usina construída após o boom de investimentos em etanol, que teve seu ápice em 2008, a entrar em recuperação judicial. Com capacidade instalada de 4,5 milhões de toneladas de cana-de-açúcar por safra, e produção estimada em 330 mil toneladas de açúcar e 150 milhões de litros de etanol anidro. É considerada a maior produtora de energia elétrica do estado, por meio da cogeração pela queima da biomassa da cana.

O plano de recuperação judicial foi homologado pela Justiça do Estado de Mato Grosso do Sul, em Setembro de 2013, prevê o parcelamento dos pagamentos de R \$1,3 bilhão de dívidas, sendo: $\mathrm{R}$ 1 bilhão com bancos, sendo $\mathrm{R}$ \$332,883 milhões com o Banco Nacional de Desenvolvimento Econômico e Social (BNDES); débitos fiscais de R\$ 30 milhões; dívidas trabalhistas, na ordem de $\mathrm{R} \$ 1,693$ milhão; e, dívidas com fornecedores, em torno de $\mathrm{R} \$ 133$ milhões.

Os débitos trabalhistas têm prioridade no pagamento, após a homologação do plano de recuperação judicial. O prazo de pagamento aos credores com garantia real será de 12 anos, contados a partir do fim de carência de três anos, com pagamento de juros em parcelas mensais, remunerados pela Taxa Referencial (TR), mais $7 \%$ ao ano. Os credores quirografários deverão ser pagos integralmente no prazo de doze anos, contados a partir do prazo de carência de quatro anos, com o pagamento de $60 \%$ do principal em 11 anos, em parcelas mensais e sucessivas, e uma parcela única de $40 \%$, mais juros de $3 \%$ anos. O plano prevê sobre a possibilidade de antecipação, parcial ou total, do pagamento dos credores com garantia real ou quirografária, na hipótese de a margem Ebtida (lucros antes dos juros, 
impostos, depreciação, depreciação e amortização) superar 35\%, após o fim da safra 2015 (CORREIO DO ESTADO, 2014; BATISTA, 2013).

A Usina Naviraí S/A - Açúcar e Álcool (Usinavi), situada no município de Naviraí/MS, juntamente com as demais empresas que compõe o Grupo Infinity Bio-Energy Brasil Participações S/A, ingressaram, com pedido de recuperação judicial, em Maio/2009, perante o Juízo da $2^{\text {a }}$ Vara de Falências e Recuperações Judiciais da Comarca de São Paulo, em razão de uma grave crise financeira. Somados os débitos trabalhistas, operações bancárias e fornecedores, a dívida total da empresa totalizava $\mathrm{R} \$ \mathrm{R} \$ 971,8$ milhões. A recuperação judicial foi a solução encontrada para assegurar a continuidade operacional das usinas Cridasa e Drisa, no Espirito Santo, Alcana e Paraíso, em Minas Gerais, e Usinavi, em Mato Grosso do Sul (CANAL DA CANA, 2009).

\section{CONCLUSÕES}

A crise financeira mundial de 2008 e a descoberta do petróleo pré-sal mudaram os rumos do setor sucroenergético brasileiro, provocando a perda de sua competitividade, sustentabilidade, eficiência e lucratividade.

A cadeia produtiva da cana-de-açúcar, desde o inicio da crise financeira mundial de 2008, vem sendo prejudicada pela falta de política governamental de apoio e incentivo à produção de combustíveis renováveis, como o etanol. São inúmeros os problemas que o inviabilizam e, precisam ser equacionados: o congelamento do preço dos combustíveis (gasolina e etanol), a extinção da CIDE na importação e comercialização da gasolina, a elevada carga tributária e a infraestrutura precária de escoamento da produção, a insuficiência de recursos de longo prazo para o financiamento e investimentos para a modernização dos parques industriais.

Além de políticas públicas especificas, o setor sucroenergético depende de vultosos investimentos para a sua recuperação, manutenção operacionalização de projetos estratégicos e expansão de sua capacidade produtiva.

Pode-se concluir que, atualmente, a cadeia produtiva brasileira da cana-de-açúcar não é sustentável, em termos econômicos, comprometendo toda a remuneração, competitividade, a manutenção de empregos, e o crescimento do setor. 
Parafraseando Neves et al. (2007), mais do que nunca, faz-se necessário um planejamento estratégico, visando o reequilíbrio e a sustentabilidade do setor, para que sejam mantidos e preservados os empregos e a distribuição de rendas.

\section{AGRADECIMENTOS E FONTES DE FINANCIAMENTO:}

À Universidade Estadual de Mato Grosso do Sul (UEMS), pela concessão de afastamento integral para capacitação em nível de Mestrado; e à Fundação de Apoio ao Desenvolvimento do Ensino, Ciência e Tecnologia do Estado de Mato Grosso do Sul (FUNDECT), e Coordenação de Aperfeiçoamento de Pessoal de Ensino Superior (CAPES) pela concessão de Bolsa em nível de Mestrado - Chamada Pública FUNDECT/CAPES no $02 / 2014$.

\section{REFERÊNCIAS}

AGENCIA ESTADO. Bunge caminha para vender ativos no Brasil, diz Pedro Parente. Sexta, 25/4/2014. <http://www.novacana.com/n/industria/usinas/bunge-vender-ativos-brasilparente-250414/>. Acesso em 5 Jul.2014

Odebrecth Agroindustrial lucra R\$ 75 mi em 2013/2014. Segunda, 14/7/2014. $<$ http://www.novacana.com/n/industria/financeiro/odebrecht-agroindustrial-lucra-r-75-mi2013-14-14072014/> Acesso em 15 Jul.2014.

AGRICUltura RURALBR. Safra de cana cresce em Mato Grosso do Sul, mas produtividade recua. 10.4.2014. <http://agricultura.ruralbr.com.br/noticia/2014/04/ safra-decana-cresce-em-mato-grosso-do-sul-mas-produtividade-recua-4471008.html $>$ Acesso em 5 Jul.2014.

AGUIAR, I.D. Etanol atravessa sua pior crise. Valor Econômico. Segunda, 28/4/2014. <http:/www.novacana.com/mercado/etanol-atravessa-pior-crise-280414/> Acesso em 5 Jul.2014.

BATISTA, F. Justiça aprova plano de recuperação judicial da Usina São Fernando. Valor Econômico. 30.9.2013. <http://www.valor.com.br/agro/3288922/justica-aprova-plano-derecuperacao-judicial-da-usina-sao-fernando > . Acesso em 5 Jul.2014.

Infinity busca recursos para operar em 2014. Valor Econômico. 27.1.2014. <http://www.novacana.com/n/industria/financeiro/infinity-busca-recursos-operar-270114/>. Acesso em 11 Ago.2014.

Expectativa de nova onda de consolidação no segmento. Valor Econômico. 6.5.2014. <http://www.novacana.com/n/industria/usinas/expectativa-onda-consolidacao segmento-060514/> Acesso em 5 Jul.2014. 
. Odebrecht fará "ajuste" na área de etanol. Valor Econômico. 7.5.2014. $<$ http://www.valor.com.br/agro/3538814/odebrecht-fara-ajuste-na-area-de-etanol>. Acesso em 5 Jul.2014

Biosev tem prejuízo líquido de $\mathrm{R} \$ 1,017$ bilhão no $4^{\circ}$ tri de 2013/2014. Valor Econômico. Quarta 11.6.2014. <http:/novacana.com/n/indústria/financeiro/bioserv-prejuizoliquido-110614> Acesso em 5 Jul.2014

Demissões na Odebrecht Agroindustrial já começaram e poderão continuar. Valor Econômico. Sexta, 19.6.2014. 8:35. <http:/novacana.com/n/indústria/ investimento/demissões-odebrecht-agroindustrial-comecaram-aumentar-190614> Acesso em 5 Jul.2014.

BIOSUL. Exportação de açúcar cresce $34 \%$ em julho ante junho, informa MDIC. Segunda, 4.8.2014 - Associação dos Produtores de Bioenergia de Mato Grosso do Sul. <http://www.biosulms.com.br/noticias/industria/exportacao-de-acucar-cresce-34-em-julhoante-junho-informa-mdic-21.html> Acesso em 7 Ago.2014.

Fórum Nacional Sucroenergético, setor atravessa pior crise. Sexta, 1.8.2014 Associação dos Produtores de Bioenergia de Mato Grosso do Sul. < http://www.biosulms.com.br/noticias/industria/forum-nacional-sucroenergetico-setoratravessa-pior-crise-17.html> Acesso em 7 Ago.2014.

BOAVENTURA, J.M.G.; CARDOSO, F.R.; SILVA, E.S.; SILVA, R.S. Teoria dos Stakeholders e Teoria da Firma: um estudo sobre a hierarquização das funções-objetivo em empresas brasileiras. Revista Brasileira de Gestão de Negócios. vol. 11, n, 32, jul.-sep./2009, pp. 289-307. Redalyc. Red. de Revistas Cientificas de America Latina, el Caribe, España y Portugal. Sistema de Información Científica. <http://www.redalyc.org/articulo.oa?id=94712655005> Acesso em: 18.7.2014.

BRASIL. Ministério da Agricultura, Pecuária e Abastecimento. Secretaria de Produção e Agroenergia. Departamento da Cana-de-Açúcar e Agroenergia. Produção brasileira de Cana-de-açúcar, Açúcar e Etanol. Setor Sucroalcooleiro. <http://www.udop.com.br/download/estatistica/acucar_producao/29jul14_\%20producao_cana _acucar_etanol.pdf> Acesso em 7 Ago.2014

BRASILAGRO. Credores buscam a raiz dos problemas da Usina São Fernando. 24.2.2014. <http://www.brasilagro.com.br/index.php?noticias/detalhes/12/55736> Acesso em 21 Jun. 2014

CANAL DA CANA. Justiça aprova recuperação da Infinity Bio-Energy. 23.jun.2009 < http://www.canaldacana.com.br/noticias-detalhes/justi-ccedil-a-aprova-recupera-ccedil-atildeo-da-infinity-bio-energy/1932/> Acesso em 11 Ago.2014.

CANASAT. Área cultivada em Mato Grosso do Sul, na safra 2013/2014. $<$ http://www.dsr.inpe.br/laf/canasat/cultivo.html> Acesso em 21 Jun.2014.

CENTENARO. M. Análise da evolução da indústria sucroenergética do Estado de Mato Grosso do Sul. Anais do Encontro Científico de Administração, Economia e Contabilidade, v. 1, n. 1 (2011). $\quad$ v.1, n.1. $2011 . \quad<$ http://periodicos.uems.br/novo/ index.php/ecaeco/article/view/1359/754> Acesso em 17 Jun.2014 
CENTENARO. M. Um estudo sobre investimento direto externo no Setor Sucroenergético do Estado de Mato Grosso do Sul. Tese de Doutorado. Programa de PósGraduação em Administração. Universidade do Vale dos Sinos. São Leopoldo RS: Unisinos, 2012.

CONFEDERAÇÃO NACIONAL DA INDÚSTRIA. Bioetanol - o futuro renovável. Fórum Nacional do Sucroenergético. Brasília DF: CNI, 2012.

CORREIO DO ESTADO. Dívida de mais de R\$ 1 bilhão leva usina do Grupo Bertin a pedir recuperação judicial. 17.3.2013. <http://www.novacana.com/n/industria /financeiro/divida-1bi-usina-grupo-bertin-recuperacao-judicial-170413/\#> Acesso em 05 Jul.2014.

FAGUNDES, P.M. As relações internacionais de interdependência no setor de etanol e suas implicações na cadeia de produção brasileira. Tese de Doutorado. Programa de PósGraduação em Agronegócios. Universidade Federal do Rio Grande do Sul. Porto Alegre: UFRGS, 2013.

FARINA, E.M.M.Q. Competitividade e coordenação de sistemas agroindustriais: Um ensaio conceitual. G\&P Gestão \& Produção. v. 5, n. 3, p. 147-161, Dez.1999.

FARINA, E.M.M.Q; SAES, M.S.M; AZEVEDO, P.F. Competitividade: mercado, estado e organizações. São Paulo: Editora Singular, 1997.

FOLHA DE CAMPO GRANDE. Setor sucroenergético de MS esbarra no custo. 18.5.2014. $\quad<$ http://www.portaldoagronegocio.com.br/noticia/setor-sucroalcooleiro-2115 /setor-sucroenergetico-de-ms-esbarra-no-custo-10650> Acesso em 5 Jun.2014.

GIANEZINI, M.; SAGGIN, K.D.; BRANDÃO, F.S.; WINCK, C.A.; RUVIARO, C.F.; LEONARD, A. Competitividade, capacidade de inovação e desenvolvimento regional: Interrelações no contexto do agronegócio suinícola no Oeste de Santa Catarina. RDE. Revista de Desenvolvimento Econômico. Ano XV, n. 27, Junho de 2013, Salvador, BA, pp. 16-24.

HARRISON, R. W.; KENNEDY, P. L. A neoclassical economic and strategic management approach to evaluating global agribusiness competitiveness.CR, Vol. 7 (1), 1997, pp. 14-25.

INSTITUTO BRASILEIRO DE GEOGRAFIA E ESTATÍSTICA - IBGE. Produção Agrícola Municipal. Culturas Temporárias e Permanentes. v. 37, p. 1-91, 2010. <http://www.ibge.gov.br/home/estatistica/economia/pam/2010/PAM2010_Publicacao_compl eta.pdf> Acesso em 20 Jun.2014.

INSTITUTO BRASILEIRO DE GEOGRAFIA E ESTATÍSTICA - IBGE. Produção Agrícola Municipal. Culturas Temporárias e Permanentes. v. 39, p. 1-98, 2012. < ftp://ftp.ibge.gov.br/Producao_Agricola/Producao_Agricola_Municipal_[anual]/2012/pam201 2.pdf> Acesso em 20 Jun.2014.

MARQUES, D.S.P.; PAULILLO, L.F.O. Cadeia do álcool combustível: o elo indústriadistribuição sob olhar da Economia dos Custos de Transação. Informações Econômicas, SP, v. 39, n. 2, Fev./2009. 
MATO GROSSO DO SUL. Secretaria de Estado de Meio Ambiente, do Planejamento, da Ciência e Tecnologia. Estudo da Dimensão Territorial do Estado de Mato Grosso do Sul: Regiões de Planejamento. Campo Grande MS: SEPLANCT, 2011.

MELLO, P.C. Política de Dilma está quebrando o etanol, diz presidente de entidade. Folha de São Paulo. 13.4.2014. <http://www1.folha.uol.com.br/poder/ 2014/04/1440253politica-de-dilma-esta-quebrando-o-etanol-diz-presidente-de-entidade.shtml> Acesso em 21 Jun.2014

MILANEZ, A.Y; NYKO, D.; GARCIA, J.L.F.; REIS, B.L.S.F.S. O déficit de produção de etanol no Brasil entre 2012 e 2015: determinantes, consequências e sugestões de politica. $\begin{array}{lllll}\text { Biocombustíveis. } & \text { BNDES } & \text { Setorial 35, } & \end{array}$ <http://www.bndes.gov.br/SiteBNDES/export/sites/default/bndes_pt/Galerias/Arquivos/conhe cimento/bnset/set3508.pdf> Acesso em 22 Jun.2014

MSANGI, S.; SULSES, T.; ROSEGRANT, M.; VALMONTE-SANTOS, R.; RINGLES, C. Global Scenarios for Biofuels: Impacts and Implications for food security and water use. Purdue University, West Lafayette, Indiana. 7-9 June 2007 <https://www.gtap.agecon.purdue.edu/resources/download/3331.pdf > Acesso em 2 Jul.2014

NASTARI, P.M. Açúcar e etanol. Contribuição para a balança comercial. Agroanalysis. Mercado \& Negócios. 18.Ago.2013.

NEVES, M.F. Caminhos da cana. Sertaozinho, SP: Canaoeste, 2014.

. CANEJERO, M.A. Sistema agroindustrial da cana: cenários e agenda estratégica. Econ. Aplic. São Paulo, v. 11, n. 4, p. 587-604, Out.-Dez./2007.

. TROMBIN, V.G. (Coord.) A dimensão do Setor Sucroenergético. Mapeamento e Quantificação da Safra 2013/2014. Ribeirão Preto SP: Markestrat, Fundace, FEA - RP/USP, 2014.

NIEDERLE, P.A. Delimitando as fronteiras entre mercados convencionais e alternativos para a agricultura familiar. Revista Extensão Rural. DEAER/PPGExR - CCR - UFSM, Ano XVI, no 18, Jul.-Dez./2009.

NORTH, D. C. Transaction Costs Institutions, and Economic Performance.An International Center for Economic Growth Publication. San Francisco, California: PRESS, 1992 <http://khosachonline.ucoz.com/ld/1/144_chi_ph_gd-th_ch.pdf> Acesso em: 16 Jul.2014.

NOVACANA. Biosev capta US\$ 440 milhões em empréstimo sindicalizado. 16.6.2014. <http://www.novacana.com/n/industria/financeiro/biosev-capta-us-440-milhoes-emprestimo160614/?> Acesso em 17 Jun.2014.

ROSÁRIO, F.J.P.; SANTA RITA, L.P.; ALBUQUERQUE, P.P.; TONHOLO, J. Organizações, instituições e tecnologia na agroindústria sucroalcooleira. Revista de $\begin{array}{llllll}\text { Economia } & \text { Mackenzie. } & 9 & (1), & \text { p. } & 119-143,\end{array}$ <http://editorarevistas.mackenzie.br/index.php/rem/article/view/3420> Acesso em Acesso em 18 Jul.2014 
UNICA. Produção de etanol atinge nível recorde, mas não ameniza crise do Setor. Folha de S. Paulo Online, 16.6.2014 <http://www.unica.com.br/unica-namidia/17629673920340519885/producao-de-etanol-atinge-nivel-recorde-por-cento 2C-masnao-ameniza-crise-do-setor/> Acesso em 17 Jun.2014

VALENTE, M.S.; NYKO, D.; REIS, B.L.S.F.S.; MILANEZ, A.Y. Bens de capital para o setor sucroenergético: a indústria está preparada para atender adequadamente a novo ciclo de investimentos em usinas de cana-de-açúcar? Bioenergia BNDES Setorial 36, p. 119-178, 2012.<http://www.bndes.gov.br/SiteBNDES/bndes/bndes_pt/Institucional/Publicacoes/Consu lta_Expressa/Tipo/BNDES_Setorial/201209_04.html> Acesso em 11 Ago.2014.

VILPOUX, O.F. Agrarian reform and cooperation between settlers in the Midwest of Brazil: An institutional approach. Land Use Policy 39 (2014) 65-77.

WILKINSON, J. A contribuição da teoria francesa das convenções para os estudos agroalimentares - algumas considerações iniciais. Ensaios FEE, Porto Alegre, v. 20, n. 2, p. 64-80, 1999.

WILLIAMSON, O.E. The economics of Organation: The Transaction Cost Approach. The University of Chicago Press. American Journal of Socioogy, vol. 87, n. 3 (Nov, 1981), pp. 548-577. 